\title{
Individual Differences Predicting Impression Management Detection in Job Interviews
}

Nicolas Roulin

University of Manitoba

Follow this and additional works at: https://scholarworks.bgsu.edu/pad

Part of the Human Resources Management Commons, Industrial and Organizational Psychology Commons, and the Other Psychology Commons

How does access to this work benefit you? Let us know!

\section{Recommended Citation}

Roulin, Nicolas (2016) "Individual Differences Predicting Impression Management Detection in Job Interviews," Personnel Assessment and Decisions: Number 2 : Iss. 1 , Article 1.

DOI: https://doi.org/10.25035/pad.2016.001

Available at: https://scholarworks.bgsu.edu/pad/vol2/iss1/1

This Main Article is brought to you for free and open access by the Journals at ScholarWorks@BGSU. It has been accepted for inclusion in Personnel Assessment and Decisions by an authorized editor of ScholarWorks@BGSU. 


\title{
Individual Differences Predicting IMPRESSION MANAgEMENT DETECTION IN JOB INTERVIEWS
}

\author{
Nicolas Roulin ${ }^{1}$
}

1. University of Manitoba

ABSTRACT

\begin{abstract}
Applicant impression management (IM), and especially its deceptive side (i.e., faking), has been described as a potential threat to the validity of employment interviews. This threat was confirmed by evidence of interviewers' inability to detect (deceptive) IM tactics. Previous studies suggested that some interviewers could be better IM detectors than others but did not examine the reasons explaining higher abilities. Building on interpersonal deception theory, this study explores individual differences in cognitions (i.e., cognitive ability) and social sensitivity (associated with generalized trust and honesty) as predictors of IM detection abilities. Results of a study with 250 individuals suggest that these individual differences did not independently predict IM detection. Although high trust was associated with higher IM detection when combined with high cognitive ability, a high-trust/low-ability combination appears to be the most harmful for detection. Organizations may consider fighting applicant deception by relying on interviewers who are high cognitive ability trusters.
\end{abstract}

impression management, deception detection, cognitive ability, personality, trust often fail to correctly detect when applicants are using IM or to differentiate honest from deceptive attempts (Roulin, Bangerter, \& Levashina, 2014, 2015). Interestingly, although these studies showed overall low IM detection abilities, they also highlighted variations between respondents. For instance, IM detection abilities of some interviewers were higher than what could be attributed to chance alone, whereas other interviewers performed below chance level. However, it was not clear what caused such variations.

This study explores the possibility that some interviewers possess specific characteristics that make them particularly effective IM detectors. Building on interpersonal deception theory (Buller \& Burgoon, 1996) and earlier deception detection research, this study examines if individuals higher in cognitions (i.e., cognitive ability) and social sensitivity (generalized trust and honesty) perform better at detecting applicant IM. It therefore contributes to the research on personnel selection, IM, and deception detection by providing initial evidence about which individual differences are associated with higher IM detection abilities in interviews.

\section{Corresponding author:}

Nicolas Roulin

Asper School of Business, University of Manitoba; 181

Freedman Crescent, Winnipeg, MB, R3T 5V4

Email: nicolas.roulin@umanitoba.ca

Phone: 204-480-1046 


\section{Impression Management in Employment Interviews}

Applicants' IM involves behaviors or tactics that individuals use to influence the impressions others have of them (Leary \& Kowalski, 1990). Such behaviors are particularly relevant in the employment interview, where applicants are motivated to create the image of a competent worker in interviewers' minds (Stevens \& Kristof, 1995). IM tactics take many forms. Examples include complimenting or flattering the interviewer or organization (i.e., ingratiation), emphasizing one's many qualifications and positive qualities (i.e., self-promotion), and providing excuses or justifications to separate oneself from negative aspects on one's record, such as being let go from a previous job (e.g., defensive tactics). Moreover, IM can be honest but could also be deceptive, when involving exaggerations, embellishments, or inventions of qualifications (Levashina \& Campion, 2006, 2007).

Research suggests that up to $97.5 \%$ of job applicants use at least one IM tactic to promote themselves, with an average of 37.25 of such tactics used per interview (Ellis, West, Ryan, \& DeShon, 2002; Stevens \& Kristof, 1995). A large proportion of applicants also engage in deceptive IM. For instance, a study with undergraduate students found that between $65 \%$ and $99 \%$ of applicants admitted using deceptive tactics in their last interview, but applicants seem to use deceptive IM to different degrees (Levashina \& Campion, 2007). Although studies about deceptive tactics have mostly been conducted with students (e.g., König, Wong, \& Cen, 2012), these tactics are also used by more experienced job seekers (Roulin et al., 2014). Because self-focused assertive tactics like self-promotion or image creation are the most popular ones (Levashina \& Campion, 2007; Stevens $\&$ Kristof, 1995), this study will focus on those forms of IM.

Although honest IM can be seen as desirable applicant behavior, deceptive IM can be problematic because less qualified individuals may use such tactics to get hired. This situation introduces a systematic source of inaccuracy in the interview process (Ellis et al., 2002; Levashina, Hartwell, Morgeson, \& Campion, 2014). Applicants' use of deceptive tactics is thus an important concern for organizations, as they do not want to hire someone who only pretended to be a good fit with the job (Arthur et al., 2010; Stewart, Darnold, Zimmerman, Parks, \& Dustin, 2010). Moreover, recent evidence with personality testing suggests that applicants who engage in deception during the selection process are also more likely to perform poorly on the job (Donovan, Dwight, \& Schneider, 2014) and to engage in counterproductive behaviors at work, such as lack of effort, absenteeism, or theft (O'Neill et al., 2013; Peterson, Griffith, Isaacson, O’Connell, \& Mangos, 2011).

\section{Impression Management Detection}

Logically, one solution for organizations is to make sure that hiring managers or interviewers are able to detect when applicants use IM tactics and to distinguish honest from deceptive attempts (Roulin et al., 2015). This information should then be used to lower evaluations of applicants who use deceptive IM or to eliminate them from the selection process (Rosenfeld, 1997). Interviewers generally believe they can detect when applicants use deceptive tactics (Robie, Tuzinski, \& Bly, 2006). However, recent research suggests a more pessimistic reality. In multiple experimental studies, Roulin et al. (2015) highlighted that detecting IM tactics is a difficult task and that interviewers can correctly detect (on average) only around $20 \%$ of tactics used by applicants. Similar results have also been found in a field study, where interviewers' perceptions of tactics used by applicants after real interviews failed to converge with the tactics actually reported by applicants (Roulin et al., 2014). These findings also converge with deception detection research showing that people's detection abilities tend to be similar to chance levels (e.g., Bond \& DePaulo, 2008; Reinhard, Scharmach, \& Müller, 2013).

It has been suggested that accurate IM detection may be possible if interviewers use and interpret appropriate cues of deception, such as speech disturbances or response latencies, while ignoring less-appropriate cues (Van Iddekinge, Raymark, \& Roth, 2005). Distinguishing honest from deceptive forms of IM should thus be more effective if interviewers rely on valid cues identified by deception detection (DePaulo et al., 2003; Sporer \& Schwandt, 2007; Vrij, Granhag, \& Porter, 2010) and IM (Schneider, Powell, \& Roulin, 2015) research, instead of stereotypical cues (e.g., gaze aversions).

In the deception detection literature, several studies demonstrate that detection is improved when people ignore nonverbal behavior and consider verbal or situational cues when assessing the veracity of a statement. For instance, analyzing response content (using techniques such as reality monitoring or criterion-based content analysis) helps classifying statements as being truthful or deceptive in an abovechance fashion (Sporer, 1997). In a study with police officers, deception detection was improved when they focused on story-related cues, such as vagueness or contradictions, instead of nonverbal cues like posture change or fidgeting (Mann, Vrij, \& Bull, 2004). Detection deception is also more accurate when judges are familiar with the situation described in the (truthful vs. deceptive) statement (Reinhard, Sporer, \& Scharmach, 2015; Reinhard, Sporer, Scharmach, \& Marksteiner, 2011). Similarly, judges provided with "content in context" cues, such as meaningful contextual information, reached an average of $75 \%$ detection accuracy (Blair, Levine, \& Shaw, 2010). 


\section{Individual Differences and IM Detection}

Another area to explore is that some interviewers may possess individual traits or characteristics making them better IM detectors. In the interview IM literature, this possibility has been only seldom researched. For instance, interviewers' gender, age, or experience does not predict IM detection abilities (Roulin et al., 2014, 2015), a finding that is consistent with earlier research on deception detection (Reinhard, Scharmach, \& Müller, 2013; Vrij et al., 2010). Overall, deception detection research has failed to uncover robust individual differences in deception detection abilities (Bond \& DePaulo, 2008). As an exception, Ekman and colleagues (e.g., Ekman, O'Sullivan, \& Frank, 1999; O'Sullivan \& Ekman, 2004) have identified individuals with exceptionally high deception detection abilities. A common characteristic of these so-called "deception wizards" was an above-average capacity to read and understand others' emotions, and to spot facial micro-expressions that were not aligned with the emotional response the person deceptively attempted to display. However, those findings have been criticized, for instance because some respondents scored their own detection test or achieved high scores on some tests but not others (Bond, 2008). Moreover, Ekman and colleagues found only 29 "wizards" in a cumulated sample of 12,000 participants, a number that can be explained by chance alone (Bond \& Uysal, 2007).

Buller and Burgoon's (1996) interpersonal deception theory (IDT) represents a pertinent framework to identify potential individual differences associated with IM detection abilities. IDT describes the mechanisms at play when senders attempt to deceive receivers, highlights how receivers interpret senders' message and behaviors, and discusses what can make some individuals better at deception detection. More precisely, IDT proposes that individuals' ability to detect when someone is using deception depends largely on cognitions and decoding abilities. IDT contends that distinguishing truthful from deceptive messages requires complex information-processing strategies, which can be prone to various cognitive biases or errors. As such, evaluators' cognitive abilities can be seen as a key component of deception (or IM) detection abilities. Moreover, IDT proposes that successful evaluators should also possess higher social sensitivity, helping them to control information, manage impressions, enact detection strategies, and judge source and message credibility. As such, I propose to examine the relationship between IM detection in employment interviews and measures of cognitions and social sensitivity in this study.

\section{Cognitions}

Buller and Burgoon's (1996) IDT suggests that evaluators should initially characterize the person they evaluate as honest but must correct this impression if cues suggesting deceptions are made available to them. Yet, such a correction is cognitively demanding, and individuals with lower cognitive capacity may fail to correct initial judgments and engage in truth bias (i.e., believing that most people are truthful; Millar \& Millar, 1997). Similarly, a dual-process approach to deception detection (Reinhard \& Sporer, 2008, 2015) suggests that individuals can engage in either effortful and systematic or effortless and heuristic-based information processing. People with high cognitive abilities (and high task involvement) can engage in systematic information processing and analyze both verbal and nonverbal cues. People with lower abilities are likely to focus on easy-toprocess (e.g., nonverbal) information only. As such, limited cognitive abilities may lead to less accurate detection, for instance because individuals would rely on the wrong cues to evaluate deception (Stiff et al., 1989).

Existing empirical evidence on the direct relationship between cognitive ability and deception detection is too scarce to reach robust conclusions (Aamodt \& Custer, 2006), but deception researchers have accumulated indirect evidence. Several studies explored evaluators' cognitions by manipulating (rather than measuring) cognitive capacity, for instance by creating high versus low cognitive load conditions. Initial examinations of the impact of cognitive load on deception detection led to mixed results (Feeley \& Young, 2000; Millar \& Millar, 1997). But recent studies have highlighted more encouraging results. For instance, consistent with dual-process theory, people facing higher cognitive load tend to rely heavily on (less valid) nonverbal cues to judge credibility (Reinhard \& Sporer, 2008). Moreover, when individuals' cognitive resources are reduced (e.g., by an ego depletion task), they experience more difficulties to analyze verbal cues and achieve lower detection accuracy (Reinhard, Scharmach, \& Stahlberg, 2013). Similarly, individuals with high need for cognition (i.e., with a higher motivation to engage in effortful cognitive endeavors) do engage in systematic information processing when facing low (vs. high) cognitive load and are better at detecting deception (Reinhard, 2010). This study aims at extending those results to assess the actual impact of measured cognitive ability. Based on the theoretical arguments and (indirect) empirical evidence suggesting that cognitive ability should foster detection, the following hypothesis is proposed:

Hypothesis 1. Cognitive ability will be positively associated with IM detection.

\section{Social Sensitivity}

Buller and Burgoon's (1996) IDT further proposes that detection should be easier for individuals possessing higher levels of social sensitivity. Higher sensitivity may help evaluators to have a calibrated level of suspicion, that 
is, give applicants the benefit of the doubt but avoid extreme cases such as being overly suspicious (i.e., leading to over-attributing deceit) or too naïve (i.e., leading to a truth bias). Social sensitivity can be linked with the concept of generalized trust (Rotter, 1971). Originally depicted as a cognitive bias (Yamagishi \& Yamagishi, 1994), generalized trust has since been suggested as a form of social intelligence (Yamagishi, 2001). Indeed, generalized trust is shaped over time through localized experiences with multiple interaction partners, such as coworkers or neighbors (Glanville \& Paxton, 2007). In the adult population, high trusters are not gullible evaluators but have accumulated experience making them more sensitive to information that predicts whether they should be suspicious or if interaction partners are likely to be trustworthy (Yamagishi, 2001). Generalized trust as a form of social intelligence (or higher sensitivity) may thus be helpful for interview IM detection, as high trusters could be more motivated (i.e., similar to a higher need for cognition) but also more able to catch applicants using deceptive tactic. In a recent study, generalized trust was positively related to deception detection (Carter \& Weber, 2010). But these results were based on a very small $(N=29)$ sample of students and only one short detection test (i.e., all students judged the same eight truthful vs. deceptive statements of applicants in a mock interview), thus limiting the generalizability of the findings. This study thus attempts to replicate and extend these results, with a larger and more heterogeneous sample, using a number of detection tests and a greater variety of responses statements, and various forms of IM tactics instead of truth/lie statements:

Hypothesis 2. Generalized trust will be positively associated with IM detection.

Buller and Burgoon's (1996) notion of social sensitivity may also be associated with personality traits. I propose to specifically examine the honesty/humility domain of the HEXACO model of personality (Lee \& Ashton, 2004). People scoring high on honesty/humility tend to value sincerity and fairness. They thus prefer interpersonal relations to be genuine than based on manipulations and are unwilling to take advantage of other individuals to gain something (Ashton, Lee, \& de Vries, 2014). High honesty/humility individuals also demonstrate more integrity and make more ethical business decisions (Lee, Ashton, Morrison, Cordery, \& Dunlop, 2008), are less likely to cheat (Hilbig \& Zettler, 2015), and are more careful towards risk taking (Weller \& Thulin, 2012). Because they strive for morality and fairness but reject cheating and are risk averse, high honesty/humility individuals may need to develop a capacity to distinguish honest from deceptive behaviors as a way to identify (and protect themselves from) cheaters in social situations. Similarly to high trusters, very honest individuals may thus also possess higher sensitivity, which could translate into a higher ability to detect applicant IM in an interview setting.
This study will thus test a final hypothesis:

Hypothesis 3. Honesty/humility will be positively associated with IM detection.

According to IDT, better detectors are those who possess a combination of both cognitions and social sensitivity. As such, one can expect interviewers who demonstrate higher cognitive abilities and possess one of the two forms of social sensitivity protecting them against cheaters (or untrustworthy individuals) to be more capable detectors. This study will thus also explore if cognitive ability and generalized trust (or honesty) interact to predict IM detection.

Moreover, because there is limited theoretical background on the potential effect of the other personality traits on IM detection abilities, no formal hypothesis is offered. But these relationships will be examined in an exploratory way.

\section{METHODS}

\section{Sample and Procedure}

Earlier research showed no differences in IM detection between novices and experts interviewers (Roulin et al., 2015). Therefore, this study used a sample drawn from the general population. A total of 360 U.S. residents were recruited from Crowdflower, an online crowdsourcing platform. Respondents were compensated USD \$5 for participating in a 45-minute online study. Although crowdsourcing-based samples have been described as providing high-quality and reliable data (Landers \& Behrend, 2015), the proportion of careless or unmotivated respondents can be nonnegligible (Huang, Curran, Keeney, Poposki, \& DeShon, 2012). Therefore, following Huang et al.'s (2012) recommendations, a series of seven indicators of response quality were used (e.g., time to complete the study or the cognitive ability test, question testing instructions comprehension, response patterns). Incomplete responses and respondents who failed at two or more of those indicators were removed from the sample, resulting in a final sample of 250 participants.

Mean age was 36.76 years $(S D=13.18)$. The sample was gender balanced ( $49 \%$ female, $51 \%$ male), with a diversity of ethnicities (71\% Caucasian, 10\% Hispanic, 8\% Asian, 5\% Black, $6 \%$ other ethnicity). Moreover, $60 \%$ of respondents had a university or college degree, $66 \%$ were currently employed, and $44 \%$ had experience as an interviewer (although the median number of interviews conducted for the "experienced" group was only 2). After signing a consent form and reading instructions about the study, participants completed an IM detection test, the personality and trust measures, a cognitive ability test, and demographic questions (in that order). 


\section{Material and Measures}

IM detection tests. Research on deception detection often relies on one test (i.e., the same set of videos showed to all respondents). To increase external validity and the generalizability of the findings, I developed nine different tests (i.e., 9 different sets of videos). The initial material preparation phase involved recruiting 10 senior Canadian business students ( 5 men, 5 women) to play the role of applicants in videotaped mock interviews. Applicants were asked three past behavioral questions measuring achievement, leadership, and persuasion skills. They were instructed to respond to each question three times, using different response strategies: (a) an honest response with only honest forms of IM (e.g., truthful self-promotion), (b) a slightly deceptive response with only moderately deceptive forms of IM (e.g., embellishments), and (c) an extremely deceptive response with strongly deceptive forms of IM (e.g., inventions). Applicants were provided with definitions and examples of each strategy, were given time to prepare their answers, and could do multiple takes of each answer if necessary. This resulted in a total of 90 short video clips (i.e., 10 applicants $\times 3$ questions $\times 3$ response types) of 60 to 90 seconds each. A total of nine different IM detection tests were created by combining one video clip from each of the 10 applicants answering the same question. I balanced the proportion of the three response strategies (2-4 of each in every condition) and counterbalanced the order of the applicants. The content of the nine detection tests can be found in Appendix I.

IM detection. Each participant was given a definition of the three response strategies (i.e., honest, slight deception, extensive deception) and was then randomly assigned to one of the nine possible IM detection tests. After each of the 10 video clips, participants had to decide which of the three strategies the applicant used. IM detection ability was computed as the proportion of correct detection (i.e., a val- ue between 0 and 1 , with 0.33 as the chance level).

Cognitive ability. Cognitive ability was measured with the 16-item $(\alpha=.73)$ International Cognitive Ability Resource (ICAR) test (Condon \& Revelle, 2014), a recently developed public measure that demonstrated convergent validity with validated tests (e.g., SAT, ACT, GRE).

Trust. The six-item $(\alpha=.87)$ measure of generalized trust from Carter and Weber (2010) was used. Example items include "most people trust others" or "most people are trustworthy". All responses were captured with a $1=$ strongly disagree to $5=$ strongly agree Likert scale.

Personality. The 60-item HEXACO (Ashton \& Lee, 2009) was used to measure the six personality traits: honesty/humility ( $\alpha=.77$; e.g., "I would never accept a bribe, even if it were very large"), emotionality ( $\alpha=.75$; e.g., "I sometimes can't help worrying about little things"), extraversion $(\alpha=.84$; e.g., "The first thing that I always do in a new place is to make friends"), agreeableness ( $\alpha=.81$; e.g., "I tend to be lenient in judging other people"), conscientiousness $(\alpha=.80$; e.g., "People often call me a perfectionist"), and openness ( $\alpha=.77$; e.g., "People have often told me that I have a good imagination"). All responses were captured with a $1=$ strongly disagree to $5=$ strongly agree Likert scale.

\section{RESULTS}

\section{IM Detection}

Means, standard deviations, and correlations among the main variables are presented in Table 1 . It can be observed that average IM detection $(M=.37, S D=.15)$ was slightly higher than chance level (i.e., .33), and this difference was significant, $t(249)=3.80, p<.01$. Moreover, IM detection ability for about half of the sample $(47 \%)$ was below chance level and the other half (53\%) above chance level (with values ranging from .00 to .80 ). There was a small but

TABLE 1 .

Means, Standard Deviations, and Correlations Among Main Variables

\begin{tabular}{lcccccccccccc}
\hline & Scale & $M$ & $S D$ & 1 & 2 & 3 & 4 & 5 & 6 & 7 & 8 & 9 \\
\hline 1. IM detection & $0-1$ & .37 & .16 & & & & & & & & & \\
2. Experience interviewing & $0 / 1$ & .44 & - & $-.15^{*}$ & & & & & & & \\
3. Openness & $1-5$ & 3.50 & .63 & -.00 & $.13^{*}$ & & & & & & \\
4. Conscientiousness & $1-5$ & 3.68 & .58 & .03 & .09 & $.38^{* *}$ & & & & & \\
5. Agreeableness & $1-5$ & 3.14 & .64 & .02 & -.00 & $.26^{* *}$ & $.18^{* *}$ & & & & \\
6. Emotionality & $1-5$ & 3.24 & .59 & -.10 & -.07 & $-.14^{*}$ & -.12 & $-.22^{* *}$ & & & \\
7. Extraversion & $1-5$ & 3.13 & .69 & -.03 & $.24^{* *}$ & $.30^{* *}$ & $.41^{* *}$ & $.32^{* *}$ & $-.23^{* *}$ & & & \\
8. Honesty/humility & $1-5$ & 3.56 & .64 & .04 & -.04 & $.28^{* *}$ & $.49^{* *}$ & $.25^{*}$ & -.03 & .09 & & \\
9. Cognitive ability & $0-16$ & 6.96 & 3.29 & .03 & -.01 & .05 & $.10^{* *}$ & -.01 & .03 & -.11 & $.13^{*}$ & \\
10. Trust & $1-5$ & 3.29 & .75 & -.02 & -.02 & $.18^{* *}$ & $.16^{*}$ & $.38^{* *}$ & -.04 & $.22^{* *}$ & $.26^{* *}$ & .09 \\
\hline
\end{tabular}

Note. $N=250 .{ }^{*} p<.05,{ }^{* *} p<.01$. 
significant difference in IM detection ability between respondent with $(M=.35, S D=.15)$ versus without $(M=.39$, $S D=.17)$ experience as interviewers, $F(1,249)=5.31, p=$ .02 . However, there was no significant difference in cognitive ability, trust, or honesty between the two groups.

\section{Main Hypotheses Testing}

The hypotheses were tested with multiple regressions (Table 2). The personality traits (except for honesty) were entered in Step 1 together with interviewing experience (dummy coded). Cognitive ability, generalized trust, and honesty were included in Step 2. Results show that none of the three key variables individually predicted IM detection. All main effect hypotheses were thus not supported. Moreover, none of the other personality traits were significantly associated with IM detection.

TABLE 2.

Multiple Regressions Predicting IM Detection

\begin{tabular}{|c|c|c|c|}
\hline Predictors & Step 1 & Step 2 & Step 3 \\
\hline Constant & $\begin{array}{l}.478^{* *} \\
(.111)\end{array}$ & $\begin{array}{l}.472 * * \\
(.115)\end{array}$ & $\begin{array}{c}.572 \\
(.312)\end{array}$ \\
\hline Experience interviewing & $\begin{array}{l}-.048^{*} \\
(.021)\end{array}$ & $\begin{array}{l}-.048^{*} \\
(.021)\end{array}$ & $\begin{array}{l}-.045^{*} \\
(.021)\end{array}$ \\
\hline Openness & $\begin{array}{l}-.001 \\
(.018)\end{array}$ & $\begin{array}{l}-.001 \\
(.018)\end{array}$ & $\begin{array}{l}-.008 \\
(.018)\end{array}$ \\
\hline Conscientiousness & $\begin{array}{l}.011 \\
(.020)\end{array}$ & $\begin{array}{l}.006 \\
(.023)\end{array}$ & $\begin{array}{l}.005 \\
(.023)\end{array}$ \\
\hline Agreeableness & $\begin{array}{l}.000 \\
(.017)\end{array}$ & $\begin{array}{l}.002 \\
(.018)\end{array}$ & $\begin{array}{l}.003 \\
(.019)\end{array}$ \\
\hline Emotionality & $\begin{array}{l}-.031 \\
(.018)\end{array}$ & $\begin{array}{l}-.030 \\
(.018)\end{array}$ & $\begin{array}{l}-.035 \\
(.018)\end{array}$ \\
\hline Extraversion & $\begin{array}{l}-.008 \\
(.017)\end{array}$ & $\begin{array}{l}-.004 \\
(.018)\end{array}$ & $\begin{array}{l}-.007 \\
(.018)\end{array}$ \\
\hline Honesty/humility & & $\begin{array}{l}.008 \\
(.019)\end{array}$ & $\begin{array}{l}.051 \\
(.079)\end{array}$ \\
\hline Cognitive ability & & $\begin{array}{l}.001 \\
(.003)\end{array}$ & $\begin{array}{l}.002 \\
(.022)\end{array}$ \\
\hline Trust & & $\begin{array}{l}-.009 \\
(.015)\end{array}$ & $\begin{array}{l}-.089 \\
(.079)\end{array}$ \\
\hline Honesty $\times$ trust & & & $\begin{array}{l}-.005 \\
(.021)\end{array}$ \\
\hline Cognitive ability $\times$ trust & & & $\begin{array}{c}.010^{*} \\
(.005)\end{array}$ \\
\hline Cognitive ability $\times$ honesty & & & $\begin{array}{l}-.009 \\
(.005)\end{array}$ \\
\hline$F$ & 1.459 & 1.032 & 1.301 \\
\hline$R^{2}$ & .035 & .037 & .062 \\
\hline
\end{tabular}

Note. $N=250$. Values are unstandardized b-values, with standard errors in parentheses; ${ }^{*} p<.05,{ }^{* *} p<.01$.

\section{Additional Analyses}

In an attempt to explore potential interactions between the main variables, two-way interactions were added in Step 3 of the regression. Results highlight a significant cognitive ability $\times$ trust interaction $(b=.010, S E=.005, p=$ .037). Figure 1 offers a visual representation of that effect. Higher IM detection was obtained by those high on both cognitive ability and trust, whereas a combination of high trust but low cognitive ability appears to be the most harmful for detection.

Finally, in order to compare the IM detection results to the traditional deception detection literature, a binary measure of honest/deceptive detection (i.e., grouping slight and extensive IM together) was also computed. Similar to previous research, the mean for detection was just above chance level $(M=.55, S D=.15)$. Again, only the cognitive ability $\times$ trust interaction was significant $(b=.010, S E=.004, p=$ $.021)$.

\section{DISCUSSION}

Applicant IM has been extensively examined in the interview literature and has been described as a potential threat to the validity of the interview process (Levashina et al., 2014). However, our limited knowledge of the actual role played by interviewers and their ability to detect and interpret IM tactics used by job applicants can prevent this line of research from advancing further. In line with recent efforts on IM or deception detection in the interview context (e.g., Reinhard, Scharmach, \& Müller, 2013; Roulin et al., 2015), this study confirms that detecting IM is a difficult task and that people perform only slightly above chance level on average.

Most importantly, this study examined antecedents of IM detection and thus contributes to the existing body of knowledge on IM, personnel selection, and deception de-

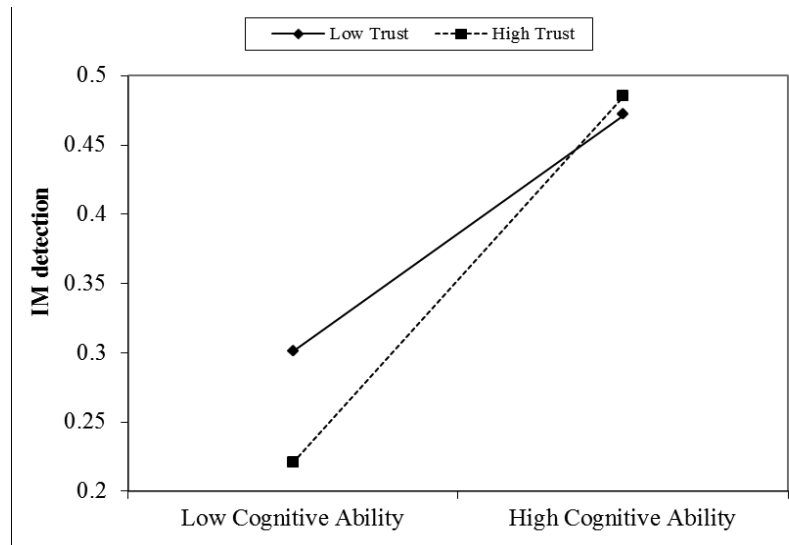

FIGURE 1. Interaction Effect of Cognitive Ability $\times$ Trust on IM Detection. 
tection. It represents a first test of cognitions or social sensitivity associated with higher deception (or IM) detection abilities discussed in Buller and Burgoon's (1996) IDT in the context of employment interviews. The results suggest that, taken separately, individual differences in cognitive abilities, generalized trust, or honesty/humility (nor any other personality traits) are not associated with IM detection. Such results differ from recent findings in deception detection research, which showed a direct effect of trust using a simpler approach to capture detection (Carter \& Weber, 2010). In this study, high trust combined with low cognitive abilities was deterring detection, whereas high trust combined with high cognitive ability was associated with higher IM detection (although not significantly higher than a high-ability/low-trust combination). IDT suggests that IM detection requires a combination of cognitions and sensitivity. These results rather suggest that sensitivity without cognitions can actually harm detection. In other words, high trusters who lack in cognitions may be naïve interviewers that are more susceptible to cognitive biases (Yamagishi \& Yamagishi, 1994). Only high trusters with high cognitions may actually possess (or have developed) a form of social intelligence (Yamagishi, 2001) making them more capable to detect applicant IM. Importantly, this study relies on an actual measure of cognitive ability, whereas existing deception detection studies have mostly manipulated cognitive resources (e.g., Feeley \& Young, 2000; Reinhard \& Sporer, 2008).

This study has important practical implications for organizations, helping them to improve their employee selection process and hiring decisions. Given the near universality of the job interview (Huffcutt \& Culbertson, 2011) and the potential negative consequences of deceptive IM on interview validity and hiring decisions (Levashina et al., 2014), organizations may benefit from selecting interviewers likely to be better IM detectors. This is especially relevant as existing evidence about the effectiveness of training for IM detection is nonexistent, and the limited evidence for deception detection does not indicate large training-related improvements (Frank \& Feeley, 2003). These findings suggest that relying on interviewers who possess a combination of high cognitive ability and trust (but avoiding those with high trust but low cognitions) may be a good way to make faking a more risky strategy for applicants (Roulin et al., 2015).

This study has limitations that create opportunities for future research. First, consistent with previous deception detection research (Bond \& DePaulo, 2008), the effects observed in this study were relatively small. Moreover, although earlier research found no difference in detection between professional interviewers and novices (e.g., Reinhard, Scharmach, \& Müller, 2013; Roulin et al., 2015), IM detection was slightly higher for respondents without than those with previous experience as interviewers. Yet, the actual experience of the 110 "experienced" individuals was still limited (e.g., a median of two interviews conducted). Future studies could replicate the results with a sample of professional HR managers or interviewers. Importantly, future research should more directly test the mechanisms enabling interviewers high on cognitive ability and trust to better detect IM, for instance examining if they rely more on valid cues to IM or if they are better able to adjust their level of suspicion when assessing applicants. Moreover, this study focused only on self-focused assertive tactics. Researchers could examine if the same effects can be found with ingratiation or defensive IM. For instance, future studies could use the same approach described in this study to test if interviewers with high trust and high cognitions can more accurately differentiate honest from deceptive forms of ingratiation (e.g., applicants truthfully describing values they share with the interviewer vs. only pretending to share those values). Researchers could also combine the findings from this study with research on deception detection training (e.g., Frank \& Feeley, 2003; Hartwig, Granhag, Strömwall, \& Kronkvist, 2006). For instance, studies could explore if training for IM detection would be more effective for individuals high in cognitive ability and trust. Finally, this study presents a novel approach to detection (using honest IM, slight deception, and extensive deception) that is less comprehensive than a live coding approach (like in Roulin et al., 2015) but can be more appropriate than basic deception detection approaches (with truths vs. lies) to examine applicants' IM tactics in future research.

In conclusion, even though much of the exiting research depicts a rather dark picture of organizations' ability to deal with the threat represented by applicant use of (deceptive) IM tactics in interviews, this study shows that there is light at the end of the tunnel, and fighting deception with cognitions and sensitivity (i.e., through trust) may be the first step in that direction.

\section{REFERENCES}

Aamodt, M. G., \& Custer, H. (2006). Who can best catch a liar? Forensic Examiner, 15, 6-11.

Arthur, W., Glaze, R. M., Villado, A. J., \& Taylor, J. E. (2010). The magnitude and extent of cheating and response distortion effects on unproctoredlnternet-based tests of cognitive ability and personality. International Journal of Selection and Assessment, 18, 1-16. doi: 10.1111/ j.1468-2389.2010.00476.x

Ashton, M. C., \& Lee, K. (2009). The HEXACO-60: A short measure of the major dimensions of personality. Journal of Personality Assessment, 91, 340-345. doi: 10.1080/00223890902935878

Ashton, M. C., Lee, K., \& de Vries, R. E. (2014). The HEXACO honesty-humility, agreeableness, and emotionality factors: A review of research and theory. Personality and Social Psychology Review, 18, 139-152. 
doi: $10.1177 / 1088868314523838$

Blair, J. P., Levine, T. R., \& Shaw, A. S. (2010). Content in context improves deception detection accuracy. Human Communication Research, 36, 423-442. doi: 10.1111/ j.1468-2958.2010.01382.x

Bond, C. F. (2008). Commentary a few can catch a liar, sometimes: Comments on Ekman and O'Sullivan (1991), as well as Ekman, O'Sullivan, and Frank (1999). Applied Cognitive Psychology, 22, 1298-1300. doi: 10.1002/ acp.1475

Bond, C. F., \& DePaulo, B. M. (2008). Individual differences in judging deception: Accuracy and bias. Psychological Bulletin, 134, 477-492. doi: 10.1037/00332909.134.4.477

Bond, C. F., \& Uysal, A. (2007). On lie detection "wizards". Law and Human Behavior, 31, 109-115. doi: $10.2307 / 4499518$

Bozeman, D. P., \& Kacmar, K. M. (1997). A cybernetic model of impression management processes in organizations. Organizational Behavior and Human Decision Processes, 69, 9-30. doi: 10.1006/obhd.1996.2669

Buller, D. B., \& Burgoon, J. K. (1996). Interpersonal deception theory. Communication Theory, 6, 203-242. doi: 10.1111/j.1468-2885.1996.tb00127.x

Carter, N. L., \& Weber, M. J. (2010). Not pollyannas: Higher generalized trust predicts lie detection ability. Social Psychological and Personality Science, 1, 274-279. doi: 10.1177/1948550609360261

Condon, D. M., \& Revelle, W. (2014). The International Cognitive Ability Resource: Development and initial validation of a public-domain measure. Intelligence, 43, 52-64. doi: 10.1016/j.intell.2014.01.004

DePaulo, B. M., Lindsay, J. J., Malone, B. E., Muhlenbruck, L., Charlton, K., \& Cooper, H. (2003). Cues to deception. Psychological Bulletin, 129, 74-118. doi: 10.1037/0033-2909.129.1.74

Donovan, J. J., Dwight, S. A., \& Schneider, D. (2014). The impact of applicant faking on selection measures, hiring decisions, and employee performance. Journal of Business and Psychology, 29, 479-493. doi: 10.1007/ s10869-013-9318-5

Ekman, P., O'Sullivan, M., \& Frank, M. G. (1999). A few can catch a liar. Psychological Science, 10, 263-266. doi: 10.1111/1467-9280.00147

Ellis, A. P. J., West, B. J., Ryan, A. M., \& DeShon, R. P. (2002). The use of impression management tactics in structured interviews: A function of question type? Journal of Applied Psychology, 87, 1200-1208. doi: 10.1037/00219010.87.6.1200

Feeley, T. H., \& Young, M. J. (2000). Self-reported cues about deceptive and truthful communication: The effects of cognitive capacity and communicator veracity. Communication Quarterly, 48, 101-119. doi: 10.1080/01463370009385585

Frank, M. G., \& Feeley, T. H. (2003). To catch a liar: Challenges for research in lie detection training. Journal of Applied Communication Research, 31, 58-75. doi: 10.1080/00909880305377

Glanville, J. L., \& Paxton, P. (2007). How do we learn to trust? A confirmatory tetrad analysis of the sources of generalized trust. Social Psychology Quarterly, 70, 230242.

Hartwig, M., Granhag, P. A., Strömwall, L. A., \& Kronkvist, O. (2006). Strategic use of evidence during police interviews: When training to detect deception works. Law and Human Behavior, 30, 603-619. doi: 10.1007/ s10979-006-9053-9

Higgins, C. A., \& Judge, T. A. (2004). The effect of applicant influence tactics on recruiter perceptions of fit and hiring recommendations: A field study. Journal of Applied Psychology, 89, 622-632. doi: 10.1037/00219010.89.4.622

Hilbig, B. E., \& Zettler, I. (2015). When the cat's away, some mice will play: A basic trait account of dishonest behavior. Journal of Research in Personality, 57, 72-88. doi: 10.1016/j.jrp.2015.04.003

Huang, J., Curran, P., Keeney, J., Poposki, E., \& DeShon, R. (2012). Detecting and deterring insufficient effort responding to surveys. Journal of Business and Psychology, 27, 99-114. doi: 10.1007/s10869-0119231-8

Huffcutt, A. I., \& Culbertson, S. S. (2011). Interviews. In S. Zedeck (Ed.), APA Handbook of Industrial and Organizational Psychology (Vol. 2: Selecting and developing members for the organization, pp. 185203). Washington, DC: American Psychological Association.

König, C. J., Wong, J., \& Cen, G. (2012). How much do Chinese applicants fake? International Journal of Selection and Assessment, 20, 247-250. doi: 10.1111/ j.1468-2389.2012.00596.x

Landers, R. N., \& Behrend, T. S. (2015). An inconvenient truth: Arbitrary distinctions between organizational, Mechanical Turk, and other convenience samples. Industrial and Organizational Psychology: Perspectives on Science and Practice, 8(2), 142-164.

Leary, M. R., \& Kowalski, R., M. (1990). Impression management: A literature review and two-component model. Psychological Bulletin, 107, 34-47. doi: 10.1037/0033-2909.107.1.34

Lee, K., \& Ashton, M. C. (2004). Psychometric properties of the HEXACO Personality Inventory. Multivariate Behavioral Research, 39, 329-358. doi: 10.1207/ s15327906mbr3902_8

Lee, K., Ashton, M. C., Morrison, D. L., Cordery, J., \& Dunlop, P. D. (2008). Predicting integrity with the HEXACO personality model: Use of self- and observer reports. Journal of Occupational and Organizational Psychology, 81, 147-167. doi: 10.1348/096317907X195175

Levashina, J., \& Campion, M. A. (2006). A model of faking likelihood in the employment interview. International Journal of Selection and Assessment, 14, 299-316. doi: 10.1111/j.1468-2389.2006.00353.x

Levashina, J., \& Campion, M. A. (2007). Measuring faking in the employment interview: Development and validation of an interview faking behavior scale. Journal of Applied Psychology, 92, 1638-1656. doi: 10.1037/0021- 
9010.92.6.1638

Levashina, J., Hartwell, C. J., Morgeson, F. P., \& Campion, M. A. (2014). The structured employment interview: Narrative and quantitative review of the research literature. Personnel Psychology, 67, 241-293. doi: 10.1111/peps.12052

Mann, S., Vrij, A., \& Bull, R. (2004). Detecting true lies: Police officers' ability to detect suspects' lies. Journal of Applied Psychology, 89, 137-149. doi: 10.1037/00219010.89.1.137

Millar, M. G., \& Millar, K. U. (1997). The effects of cognitive capacity and suspicion on truth bias. Communication Research, 24, 556-570. doi: 10.1177/009365097024005005

O'Sullivan, M., \& Ekman, P. (2004). The wizards of deception detection. In P. A. Granhag \& L. A. Strömwall (Eds.), The detection of deception in forensic contexts (pp. 269286). Cambridge, NY: Cambridge University Press.

O’Neill, T. A., Lee, N. M., Radan, J., Law, S. J., Lewis, R. J., \& Carswell, J. J. (2013). The impact of "non-targeted traits" on personality test faking, hiring, and workplace deviance. Personality and Individual Differences, 55, 162-168. doi: 10.1016/j.paid.2013.02.027

Peterson, M. H., Griffith, R. L., Isaacson, J. A., O'Connell, M. S., \& Mangos, P. M. (2011). Applicant faking, social desirability, and the prediction of counterproductive work behaviors. Human Performance, 24, 270-290. doi: 10.1080/08959285.2011.580808

Reinhard, M.-A. (2010). Need for cognition and the process of lie detection. Journal of Experimental Social Psychology, 46, 961-971. doi: 10.1016/ j.jesp.2010.06.002

Reinhard, M. -A., Scharmach, M., \& Müller, P. (2013). It's not what you are, it's what you know: Experience, beliefs, and the detection of deception in employment interviews. Journal of Applied Social Psychology, 43, 467-479. doi: 10.1111/j.1559-1816.2013.01011.x

Reinhard, M.-A., Scharmach, M., \& Stahlberg, D. (2013). Too exhausted to see the truth: Ego depletion and the ability to detect deception. British Journal of Social Psychology, 52, 618-630. doi: 10.1111/j.20448309.2012.02113.x

Reinhard, M.-A., \& Sporer, S. L. (2008). Verbal and nonverbal behaviour as a basis for credibility attribution: The impact of task involvement and cognitive capacity. Journal of Experimental Social Psychology, 44, 477488. doi: 10.1016/j.jesp.2007.07.012

Reinhard, M.-A., \& Sporer, S. L. (2015). Content versus source cue information as a basis for credibility judgments. Social Psychology, 41, 93-104. doi: 10.1027/1864-9335/a000014

Reinhard, M.-A., Sporer, S. L., \& Scharmach, M. (2015). Perceived familiarity with a judgmental situation improves lie detection ability. Swiss Journal of Psychology, 72, 53-61. doi: 10.1024/1421-0185/ a000098

Reinhard, M.-A., Sporer, S. L., Scharmach, M., \& Marksteiner, T. (2011). Listening, not watching: situational familiarity and the ability to detect deception. Journal of
Personality and Social Psychology, 101, 467-484. doi: 10.1037/a0023726

Robie, C., Tuzinski, K. A., \& Bly, P. R. (2006). A survey of assessor beliefs and practices related to faking. Journal of Managerial Psychology, 21, 669-681. doi: 10.1108/02683940610690204

Rosenfeld, P. (1997). Impression management, fairness, and the employment interview. Journal of Business Ethics, 16, 801-808. doi: 1023/A:1017972627516

Rotter, J. B. (1971). Generalized expectancies for interpersonal trust. American Psychologist, 26, 443452. doi: $10.1037 / \mathrm{h} 0031464$

Roulin, N., Bangerter, A., \& Levashina, J. (2014). Interviewers' perceptions of impression management in employment interviews. Journal of Managerial Psychology, 29, 141-163. doi: 10.1108/JMP-10-20120295

Roulin, N., Bangerter, A., \& Levashina, J. (2015). Honest and deceptive impression management in the employment interview: Can it be detected and how does it impact evaluations? Personnel Psychology, 68, 395-444. doi: 10.1111/peps. 12079

Roulin, N., Krings, F., \& Binggeli, S. (2015). A dynamic model of applicant faking. Organizational Psychology Review. doi: 10.1177/2041386615580875

Schneider, L., Powell, D. M., \& Roulin, N. (2015). Cues to deception in the employment interview. International Journal of Selection and Assessment, 23, 182-190. doi: 10.1111/ijsa.12106

Sporer, S. L. (1997). The less travelled road to truth: Verbal cues in deception detection in accounts of fabricated and self-experienced events. Applied Cognitive Psychology, 11, 373-397. doi: 10.1002/(SICI)10990720(199710)11:5<373::AID-ACP461>3.0.CO;2-0

Sporer, S. L., \& Schwandt, B. (2007). Moderators of nonverbal indicators of deception: A meta-analytic synthesis. Psychology, Public Policy, and Law, 13, 1-34. doi: 10.1037/1076-8971.13.1.1

Stevens, C. K., \& Kristof, A. L. (1995). Making the right impression: A field study of applicant impression management during job interviews. Journal of Applied Psychology, 80, 587-606. doi: 10.1037/00219010.80.5.587

Stewart, G. L., Darnold, T. C., Zimmerman, R. D., Parks, L., \& Dustin, S. L. (2010). Exploring how response distortion of personality measures affects individuals. Personality and Individual Differences, 49, 622-628. doi: 10.1016/ j.paid.2010.05.035

Stiff, J. B., Miller, G. R., Sleight, C., Mongeau, P., Garlick, R., \& Rogan, R. (1989). Explanations for visual cue primacy in judgments of honesty and deceit. Journal of Personality and Social Psychology, 56, 555-564. doi: 10.1037/0022-3514.56.4.555

Van Iddekinge, C. H., Raymark, P. H., \& Roth, P. L. (2005). Assessing personality with a structured employment interview: Construct-related validity and susceptibility to response inflation. Journal of Applied Psychology, 90, 536-552. doi: 10.1037/0021-9010.90.3.536

Vrij, A., Granhag, P. A., \& Porter, S. (2010). Pitfalls and 
opportunities in nonverbal and verbal lie detection. Psychological Science in the Public Interest, 11, 89-121. doi: 10.1177/1529100610390861

Weiss, B., \& Feldman, R. S. (2006). Looking good and lying to do it: Deception as an impression management strategy in job interviews. Journal of Applied Social Psychology, 36, 1070-1086. doi: 10.1111/j.00219029.2006.00055.x

Weller, J. A., \& Thulin, E. W. (2012). Do honest people take fewer risks? Personality correlates of risk-taking to achieve gains and avoid losses in HEXACO space. Personality and Individual Differences, 53, 923-926. doi: 10.1016/j.paid.2012.06.010

Yamagishi, T. (2001). Trust as a form of social intelligence. In K. S. Cook (Ed.), Trust in society (pp. 121-147). New York, NY: Russell Sage.

Yamagishi, T., \& Yamagishi, M. (1994). Trust and commitment in the United States and Japan. Motivation and Emotion, 18, 129-166. doi: 10.1007/BF02249397

RECEIVED 8/21/15 ACCEPTED 2/15/16 


\section{APPENDIX I.}

\section{Content and Links for the Nine IM Detection Tests}

\begin{tabular}{|c|c|c|c|c|c|c|c|c|c|c|}
\hline \multicolumn{11}{|c|}{ Test \# 1 - Achievement question } \\
\hline Applicant & 3 & 4 & 9 & 10 & 1 & 2 & 7 & 8 & 5 & 6 \\
\hline IM tactic & $\mathrm{E}$ & $\mathrm{S}$ & $\mathrm{H}$ & $\mathrm{E}$ & $\mathrm{H}$ & $\mathrm{S}$ & $\mathrm{E}$ & $\mathrm{H}$ & $\mathrm{H}$ & $\mathrm{S}$ \\
\hline \multicolumn{11}{|c|}{ Test \# 2 - Leadership question } \\
\hline \multicolumn{11}{|c|}{ https://www.youtube.com/watch?v=kE63uoT02s0 } \\
\hline Applicant & 1 & 2 & 3 & 4 & 5 & 6 & 7 & 8 & 9 & 10 \\
\hline IM tactic & $\mathrm{H}$ & $\mathrm{S}$ & E & $\mathrm{S}$ & $\mathrm{H}$ & $\mathrm{S}$ & E & $\mathrm{H}$ & $\mathrm{H}$ & $\mathrm{E}$ \\
\hline \multicolumn{11}{|c|}{ Test \# 3 - Persuasion question } \\
\hline \multicolumn{11}{|c|}{ https://www.youtube.com/watch?v=KLuQxZY_KC0 } \\
\hline Applicant & 4 & 5 & 6 & 1 & 2 & 3 & 9 & 7 & 8 & 10 \\
\hline IM tactic & $\mathrm{S}$ & $\mathrm{H}$ & $\mathrm{S}$ & $\mathrm{H}$ & $\mathrm{S}$ & $\mathrm{E}$ & $\mathrm{H}$ & $\mathrm{E}$ & $\mathrm{H}$ & $\mathrm{E}$ \\
\hline \multicolumn{11}{|c|}{ Test \# 4-Achievement question } \\
\hline \multicolumn{11}{|c|}{ https://www.youtube.com/watch?v=CUXydhTOHDs } \\
\hline Applicant & 10 & 9 & 4 & 3 & 6 & 5 & 2 & 1 & 8 & 7 \\
\hline IM tactic & $\mathrm{H}$ & $\mathrm{E}$ & $\mathrm{E}$ & $\mathrm{H}$ & $\mathrm{H}$ & $\mathrm{E}$ & $\mathrm{E}$ & $\mathrm{S}$ & $\mathrm{E}$ & $\mathrm{S}$ \\
\hline \multicolumn{11}{|c|}{ Test \# 5 - Leadership question } \\
\hline \multicolumn{11}{|c|}{ https://www.youtube.com/watch? $v=$ TerNajCuwy0 } \\
\hline Applicant & 10 & 9 & 8 & 7 & 6 & 5 & 4 & 3 & 2 & 1 \\
\hline IM tactic & $\mathrm{S}$ & $\mathrm{E}$ & $\mathrm{E}$ & S & $\mathrm{H}$ & $\mathrm{E}$ & $\mathrm{H}$ & $\mathrm{H}$ & $\mathrm{E}$ & $\mathrm{S}$ \\
\hline
\end{tabular}

\section{Test \# 6 - Persuasion question}

https:/www.youtube.com/watch?v=Hmvv6oa0Hes

\begin{tabular}{ccccccccccc} 
Applicant & 9 & 8 & 7 & 10 & 4 & 2 & 1 & 6 & 5 & 3 \\
IM tactic & $\mathrm{E}$ & $\mathrm{E}$ & $\mathrm{S}$ & $\mathrm{H}$ & $\mathrm{E}$ & $\mathrm{E}$ & $\mathrm{S}$ & $\mathrm{H}$ & $\mathrm{E}$ & $\mathrm{H}$ \\
\hline \multicolumn{10}{c}{ Test \# 7 - Achievement question } \\
Applicant & 5 & 2 & 8 & 6 & 3 & 9 & 1 & 7 & 4 & 10 \\
IM tactic & $\mathrm{S}$ & $\mathrm{H}$ & $\mathrm{S}$ & $\mathrm{E}$ & $\mathrm{S}$ & $\mathrm{S}$ & $\mathrm{E}$ & $\mathrm{H}$ & $\mathrm{H}$ & $\mathrm{S}$ \\
\hline
\end{tabular}

\section{Test \# 8 - Leadership question}

https://www.youtube.com/watch?v=691Yw-azSPI

\begin{tabular}{ccccccccccc} 
Applicant & 6 & 5 & 4 & 10 & 3 & 9 & 2 & 8 & 1 & 7 \\
IM tactic & $\mathrm{E}$ & $\mathrm{S}$ & $\mathrm{E}$ & $\mathrm{H}$ & $\mathrm{S}$ & $\mathrm{S}$ & $\mathrm{H}$ & $\mathrm{S}$ & $\mathrm{E}$ & $\mathrm{H}$ \\
\hline
\end{tabular}

\section{Test \# 9 - Persuasion question}

https://www.youtube.com/watch? $\mathrm{v}=6 \mathrm{~B}-\mathrm{BwrAwUYU}$

$\begin{array}{lllllllllll}\text { Applicant } & 4 & 10 & 6 & 5 & 2 & 1 & 7 & 3 & 9 & 8\end{array}$

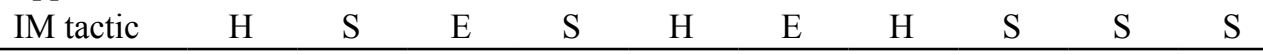

Note. $\mathrm{H}=$ Honest IM, $\mathrm{S}=$ Slightly deceptive IM, and $\mathrm{E}=$ Extensively deceptive IM. 